\title{
Comparative efficacy and safety between amisulpride and olanzapine in schizophrenia treatment and a cost analysis in China: a systematic review, meta- analysis, and cost-minimization analysis
}

\author{
Peng Men ${ }^{1,2,3 \dagger}$, Zhanmiao $\mathrm{Yi}^{1,2,3 \dagger}$, Chaoyun $\mathrm{Li}^{4}$, Shuli Qu ${ }^{5}$, Tengbin Xiong ${ }^{6}$, Xin Yu ${ }^{6}$ and Suodi Zhai ${ }^{1,2^{*}}$
}

\begin{abstract}
Background: Amisulpride was introduced into China in 2010 as a second-generation atypical antipsychotic, while olanzapine has been on the market since 1999 as one of the leading treatments for schizophrenia in China. Since more Chinese patients are gaining access to amisulpride, the study aims to compare the efficacy, safety, and costs between amisulpride and olanzapine for schizophrenia treatment in China.

Methods: PubMed, Embase, the Cochrane library, China National Knowledge Infrastructure (CNKI) and WanFang database were systematically searched for randomized controlled trials (RCTs) up to July 2018. The Cochrane Risk of Bias tool was utilized to assess the quality of included studies. A meta-analysis was performed to compare the efficacy and safety of amisulpride and olanzapine, followed by a cost-minimization analysis using local drug and medical costs reported in China.

Results: Twenty RCTs with 2000 patients were included in the systematic review. There were no significant differences between amisulpride and olanzapine on efficacy measures based on scores from the Positive and Negative Syndrome Scale, the Scale for the Assessment of Negative Symptoms, the Brief Psychiatric Rating Scale and the Clinical Global Impressions-Severity or Improvement. For safety outcomes, amisulpride was associated with lower fasting blood glucose and less abnormal liver functions as well as significantly lower risks of weight gain, constipation, and somnolence; olanzapine was associated with significantly lower risks of insomnia and lactation/amenorrhea/sexual hormone disorder. No significant differences were found in risks of extrapyramidal symptoms (EPS), tremor, akathisia, abnormal corrected QT interval. Cost-minimization analysis showed that amisulpride was likely to be a costsaving alternative in China, with potential savings of 1358 Chinese Yuan (CNY) per patient for a three-month schizophrenia treatment compared with olanzapine.

Conclusion: As the first meta-analysis and cost-minimization analysis comparing the efficacy, safety and cost of amisulpride and olanzapine within a Chinese setting, the study suggests that amisulpride may be an effective, welltolerated, and cost-saving antipsychotic drug alternative in China.
\end{abstract}

Keywords: Amisulpride, Olanzapine, Schizophrenia, Meta-analysis, Cost-minimization analysis, China

\footnotetext{
* Correspondence: zhaisuodi@163.com

${ }^{\dagger}$ Peng Men and Zhanmiao Yi contributed equally to this work.

'Department of Pharmacy, Peking University Third Hospital, N. Huayuan Rd,

Beijing, China

${ }^{2}$ Institute for Drug Evaluation, Peking University Health Science Center,

Beijing, China

Full list of author information is available at the end of the article
}

(c) The Author(s). 2018 Open Access This article is distributed under the terms of the Creative Commons Attribution 4.0 International License (http://creativecommons.org/licenses/by/4.0/), which permits unrestricted use, distribution, and reproduction in any medium, provided you give appropriate credit to the original author(s) and the source, provide a link to the Creative Commons license, and indicate if changes were made. The Creative Commons Public Domain Dedication waiver (http://creativecommons.org/publicdomain/zero/1.0/) applies to the data made available in this article, unless otherwise stated. 


\section{Background}

As a chronic and severe mental disorder, schizophrenia is associated with psychotic behaviors such as hallucinations, delusions, thought/movement disorders which are not generally seen in healthy people (positive symptoms), and disruptions to normal emotions and behaviors (negative symptoms) [1]. Schizophrenia patients may also suffer from functional impairments that consequently affect their social relationships and employment opportunities.

Globally, schizophrenia affected more than 23 million people in 2015. It was among the top ten causes of disability in adolescents and young adults aged between 15 and 39 [2]. A previous study estimated its prevalence in China and reported a two-fold increase in the number of patients, which increased from 3.09 million in 1990 to 7.16 million in 2010 [3]. Another meta-analysis [4] estimated that the lifetime prevalence of schizophrenia among Chinese people was 5.44 per 1000 in 2014, which means that there were 7.4 million patients with schizophrenia in China (the Chinese population was 1.364 billion in 2014). Also, the stigma faced by schizophrenia patients as well as their families is still common in Chinese society, therefore often impeding the access and continuity of disease treatment [5].

The economic burden of schizophrenia is heavy in China. The chronically debilitating course of disease and relapses during early and late stages of schizophrenia imply the requirement for long-term continuous treatment, which imposes a considerable economic burden on healthcare systems [6]. Total direct and indirect costs for schizophrenia treatment in China range from 94 million to 102 billion US dollar annually [7]. Data obtained from the Tianjin Urban Employee Basic Medical Insurance (UEBMI) showed an annual, schizophrenia-related, mean direct cost of 1775 US dollar per patient, with hospitalized patients spending much more than nonhospitalized patients [8].

Antipsychotics are the core treatment measures for schizophrenia [9]. Atypical antipsychotics, also known as second-generation antipsychotics, are the most commonly prescribed medications. Among them, amisulpride was introduced into China in 2010, while olanzapine has been on the market since 1999 and is currently one of the leading treatments for schizophrenia in China. Olanzapine developed quickly after entering the Chinese market, with annual sales rising from less than 40 million Chinese Yuan (CNY) in 2005 to 420 million CNY in 2014; during this period, the compound annual growth rate for olanzapine reached $30 \%$ [10].

Studies have been conducted to investigate amisulpride in comparison with other atypical antipsychotics in different populations. A Cochrane systematic review published in 2010 summarized corresponding clinical outcomes and found that the efficacy of amisulpride was similar to that of olanzapine and risperidone, and better than that of ziprasidone. Amisulpride was likely to be associated with less weight gain than risperidone and olanzapine [11]. However, the review contained no studies performed on Chinese patients. Ever since amisulpride was introduced into China in 2010, numerous studies comparing various efficacy and safety outcomes between amisulpride and olanzapine have been performed. Since an increasing number of Chinese patients have potential access to amisulpride, it is necessary to synthesize the available evidence through a systematic review and meta-analysis.

Given the economic burden of schizophrenia, the medical costs of amisulpride and olanzapine treatment are also of vital importance. Moreover, local economic evidence is increasingly required and used by relevant authorities in China during pricing and reimbursement decision-making. Appropriate treatment choices may reduce patient financial burden as well as medical insurance costs. Although economic analyses of atypical antipsychotics have been performed in some countries, China has yet to do the same [12-14].

Therefore, the objectives of this study were to 1) summarize and investigate the clinical efficacy and safety profiles of amisulpride and olanzapine as schizophrenia treatments through a systematic and repeatable evaluation of both Chinese and foreign randomized-controlled trials (RCTs); and 2), assess the costs of amisulpride and olanzapine (from a healthcare system perspective) for the treatment of schizophrenia in China.

\section{Methods}

\section{Systematic review}

The methods for systematic review adhered to guidelines published by Cochrane Collaboration [15] and the UK's National Institute for Health and Clinical Excellence (NICE) [16]. NICE has a rigorous specified approach to perform systematic reviews, and the standard is generally considered sufficient by other countries' health technology assessment agencies. The systematic review with meta-analysis was registered on PROSPERO (No. CRD 42017069524).

To identify the relevant published studies for clinical data, PubMed, Embase and the Cochrane Library were searched for RCT literature in English, and the China National Knowledge Infrastructure (CNKI) and WanFang database were searched for RCTs references in Chinese. RCTs with head-to-head comparisons between amisulpride and olanzapine were of interest. In English databases, we combined disease terms (schizophrenia) AND intervention terms (amisulpride AND olanzapine) AND study design terms (RCT, clinical trials) AND outcomes. The search terms were translated into Chinese when we searched CNKI and WanFang database. Searches were conducted separately for each literature 
Table 1 PICOS statement for inclusion and exclusion criteria

\begin{tabular}{lll}
\hline & Inclusion Criteria & Exclusion Criteria \\
\hline Study population & $\begin{array}{l}\text { Schizophrenia patients, regardless of their age, sex, ethnic } \\
\text { group or disease status. }\end{array}$ & Any not listed in the inclusion criteria \\
Intervention & Amisulpride in any oral form of application with any dose & Any not listed in the inclusion criteria \\
Comparator & Olanzapine in any oral form of application with any dose & Any not listed in the inclusion criteria \\
Outcome measures & Clinical efficacy outcomes & Any not listed in the inclusion criteria \\
Study design & RCTs with head-to-head comparison & \\
& & Editorials OR Notes OR Comments OR \\
& Full-text published manuscripts in English or Chinese & Letters OR Case reports OR Pharmacokinetic \\
Restrictions & Studies OR Epidemiology studies \\
& & Duplicates \\
& Not full-text published manuscripts \\
\end{tabular}

database up to January 2017. A complementary search was performed in order to cover the most recent articles (published before July 2018). Reference lists of identified studies and relevant systematic reviews were also screened to ensure that relevant items were not missed in the search. The scope of each search strategy has been defined and reported in the PICOS statements in Table 1.

Two reviewers (MP, YZ) independently extracted all the data. The disagreement was solved by discussion and further inspection of articles. A data extraction table was developed in Microsoft Excel to integrate data from included trials. General information regarding the identification of publication, such as author, title, year of publication, and study design were extracted. In addition, data on sample size (completed/all enrolled), patient characteristics, treatment arm characteristics, outcomes of efficacy and safety were also documented. For studies with multiple arms, only information on amisulpride and olanzapine groups was extracted.

Clinical efficacy endpoints were assessed by the mean change from baseline to total score for four common rating scales of schizophrenia: Positive and Negative Syndrome Scale (PANSS), Scale for the Assessment of Negative Symptoms (SANS), the Brief Psychiatric Rating Scale (BPRS), and the Clinical Global Impressions -

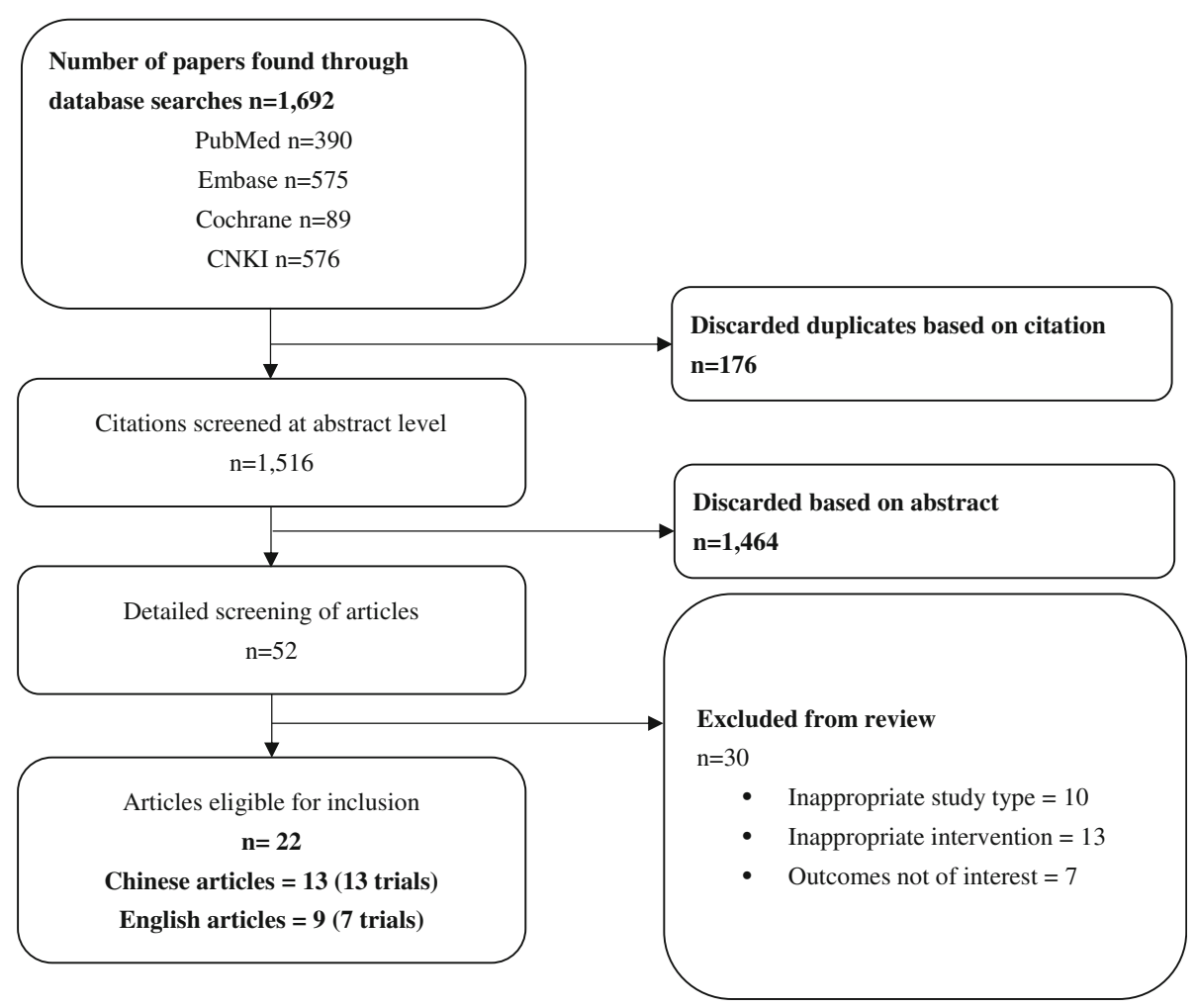

Fig. 1 Selection process for articles in the systematic review 


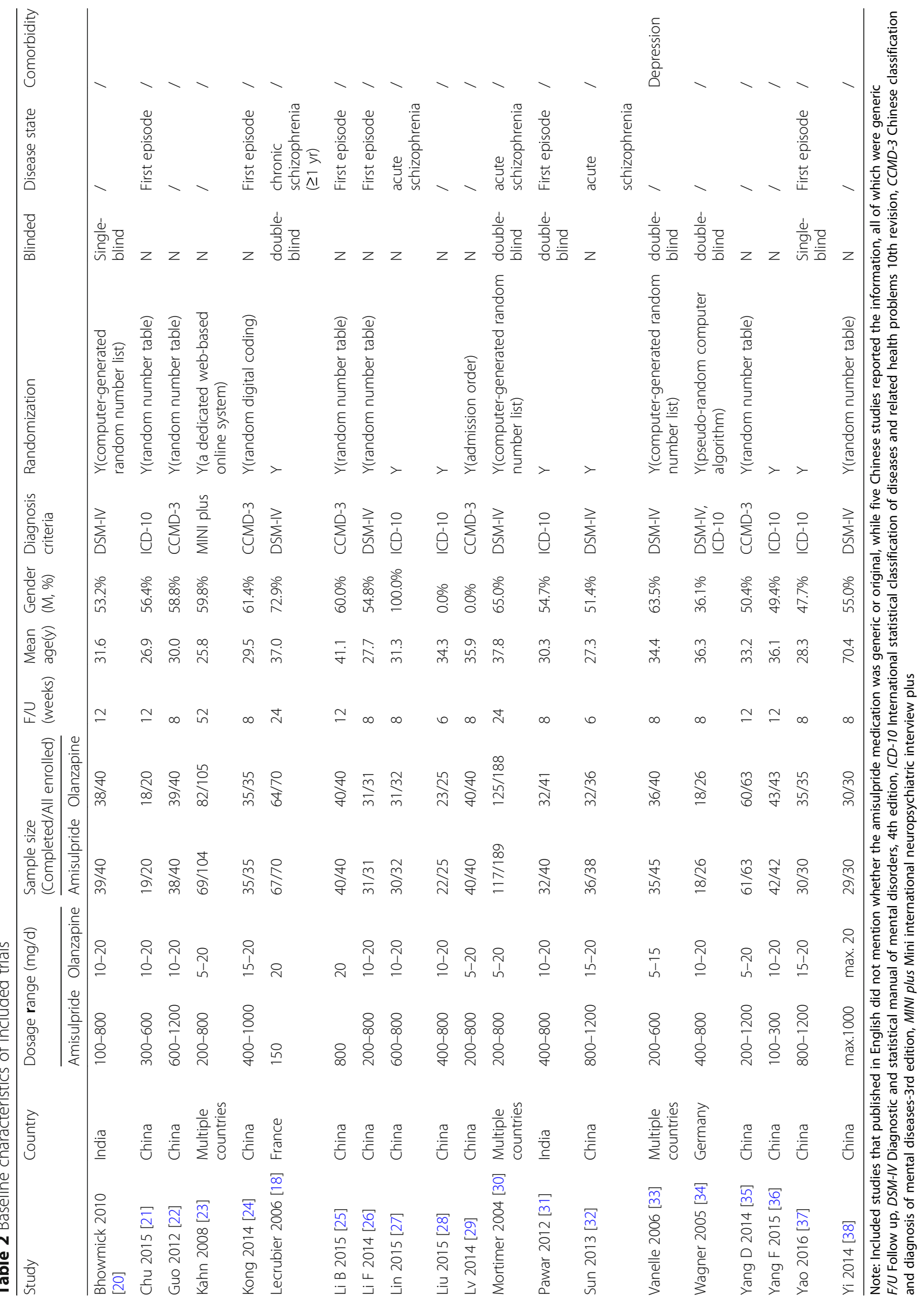


Severity or Improvement (CGI-SI). Regarding PANSS, the proportion of patients were also defined as "improved" ( $25 \%$ to no more than $50 \%$ reduction in PANSS score), "much improved" (50\% to no more than $75 \%$ reduction in PANSS score), or "very much improved" (more than $75 \%$ reduction in PANSS score).

Safety outcome endpoints included extrapyramidal symptoms (EPS), weight gain, metabolic parameters (total cholesterol, high-density lipoprotein (HDL), low-density lipoprotein (LDL), triglycerides and blood glucose), headache, insomnia, somnolence, xerostomia, increased salivation, constipation, hypotension and abnormal corrected QT interval (QTc).

The Cochrane Collaboration's tool for assessing risk of bias was employed to assess the methodological quality of included RCTs [17]. Two reviewers independently assessed six domains, which comprised of selection bias (random sequence generation and allocation concealment), performance bias (blinding of participants and personnel), detection bias (blinding of outcome assessment), attrition bias (incomplete outcome data), reporting bias (selective reporting) and other sources of biases. The risk of bias in each domain was categorized as "low", "high" or "unclear".

\section{Meta-analysis}

Risk ratios (RRs) and weighted mean differences (WMDs) with 95\% confidence intervals (CIs) were calculated for dichotomous and continuous outcomes respectively. A $p<0.05$ was considered statistically significant. Meta-analysis was performed using STATA (version 12; Stata Corp., College Station, Texas, USA). Heterogeneity was assessed by Cochran's Q statistic and $I^{2}$ statistic. The significance of the Q-statistic test with $P<0.10$ indicated a substantial level of heterogeneity. The $I^{2}$ statistic revealed that the percentage of variability in effect estimates was the result of heterogeneity rather than sampling error, where $I^{2}$ values of $50 \%$ or more implied a substantial level of heterogeneity. The fixed effects model was utilized for $I^{2}$ values lower than 50\% and the Q-statistic test $p$ values greater than 0.10 ; otherwise, the random effects model was used. The pooled results were displayed using forest plots.

\section{Cost-minimization analysis}

Following the meta-analysis, a Microsoft Excel-based cost-minimization analysis (CMA) was conducted to compare the local drug and medical costs between amisulpride and olanzapine for schizophrenia patients in China.

IQVIA China Hospital Pharmaceutical Audit (CHPA) database served as the primary data source for retrieving associated drug acquisition costs in China's setting. The CHPA database reports the market purchase prices at which the panel hospitals purchase products from wholesalers, distributors, and manufacturers. Database findings showed that the unit costs of original and generic drugs varied greatly in China. Because both Chinese and foreign studies were included in the meta-analysis, and several Chinese studies used generic amisulpride and olanzapine in the trials, we conducted the CMA in two scenarios in order to differentiate the impact of original and generic drug costs. In the base case analysis, we applied weighted-average drug costs for both original and generic drugs, while in an additional scenario, we only applied the average cost of original drugs in the model. All resource costs were represented in CNY.

Weighted-average dosages from included trials of the systematic review were calculated and applied in the CMA. The time horizon of the CMA was based on the average duration of follow-up of included studies.

\begin{tabular}{|c|c|c|c|c|c|c|c|c|c|c|c|c|c|c|c|c|c|c|c|}
\hline $\begin{array}{l}\frac{\mathrm{g}}{\mathrm{O}} \\
\mathrm{O} \\
\mathrm{O}\end{array}$ & 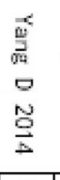 & 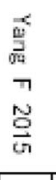 & 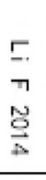 & 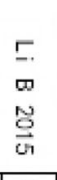 & $\begin{array}{l}\leq \\
\leq \\
\underline{\tilde{O}}\end{array}$ & 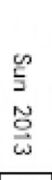 & 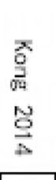 & & & $\begin{array}{l}\frac{F}{C} \\
\bar{O} \\
\mathcal{O} \\
\mathcal{G}\end{array}$ & $\begin{array}{l}\bar{Y} \\
\bar{G} \\
\stackrel{y}{G}\end{array}$ & $\begin{array}{l}\frac{\mathrm{O}}{\mathrm{c}} \\
\tilde{\mathrm{O}} \\
\mathrm{v}\end{array}$ & 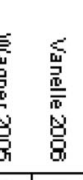 & 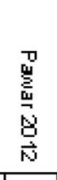 & 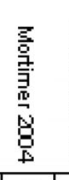 & 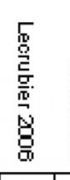 & 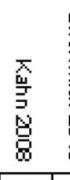 & 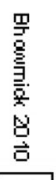 & \\
\hline+ & + & $\infty$ & + & 4 & + & $v$ & + & $\omega$ & 0 & $v$ & $v$ & 9 & +9 & $\omega$ & + & \begin{tabular}{|l|l} 
& \\
\end{tabular} & \begin{tabular}{|l|l}
+ & \\
\end{tabular} & + & Randomsequence generation (selection bizz) \\
\hline$\omega$ & $\omega$ & $\omega$ & $\omega$ & $\omega$ & $\omega$ & $\omega$ & $\omega$ & $\omega$ & $\omega$ & $\omega$ & $\omega$ & $\omega$ & 4 & $\omega$ & + & $\sim$ & $\omega$ & $s$ & Allocation conce alment (selection bias) \\
\hline 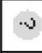 & 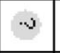 & $\infty$ & $\omega$ & $\omega$ & $\omega$ & $\theta$ & + & + & $\theta$ & $\omega$ & $\omega$ & $\omega$ & + & + & + & + & \begin{tabular}{|l|} 
\\
\end{tabular} & + & Elinding of participants and personnel(performance bix: \\
\hline$\omega$ & $\omega$ & $\infty$ & $\omega$ & $\omega$ & $\omega$ & $\omega$ & + & + & $\omega$ & $\omega$ & $\omega$ & 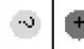 & + & + & + & + & $\omega$ & + & Elinding of outome assessment (detection bias) \\
\hline+ & 4 & $\oplus$ & + & + & + & + & 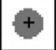 & 4 & $\oplus$ & $\oplus$ & + & $\oplus$ & + & + & + & +1 & +1 & + & Incomplete outcome data (attrition bixz) \\
\hline+ & + & + & + & + & $\oplus$ & + & + & + & + & + & + & +4 & +4 & + & + & +1 & + & + & Selective reporting (reporting bizz) \\
\hline+ & + & $\omega$ & + & + & + & + & $\approx$ & + & 4 & $\omega$ & + & $4+$ & +9 & 0 & + & +4 & +1 & + & Other bias \\
\hline
\end{tabular}


Randorn sequence generation (selection bias)

Allocation concealment (selection bias)

Blinding of participants and personnel (perform ance bias)

Elinding of outcome assessment (detection bias)

Incomplete outcome data (attrition bias)

Selective reporting (reporting bias)

Other bias
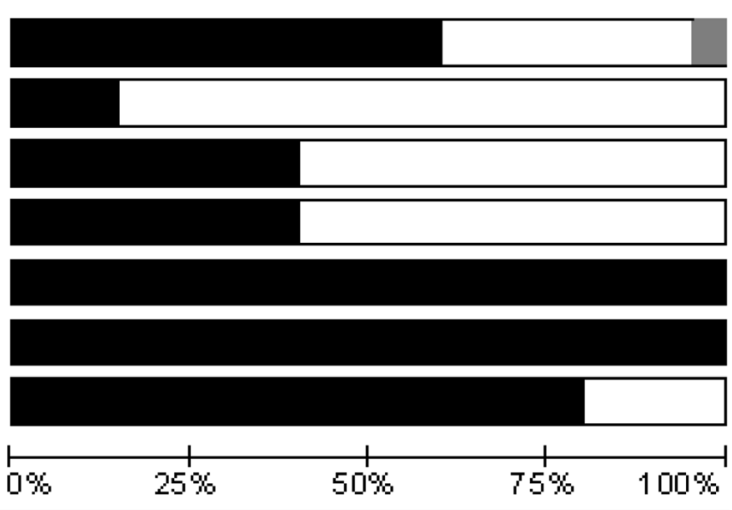

Lowrisk of bias

Unclear risk of bias

High risk of bias

Fig. 3 Summary of risk of bias assessment

\section{a}

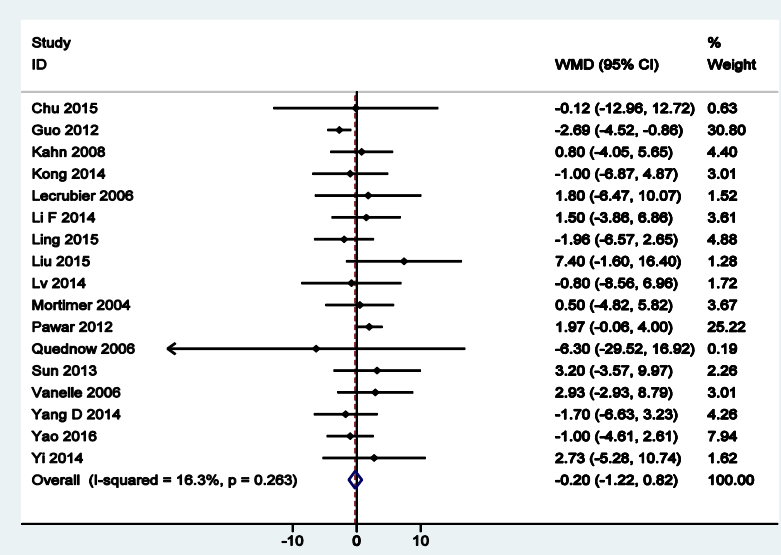

C

Study

ID

Bhowmick 2010

Lecrubier 2008

Mortimer 2004

Pawar 2012

Vanelle 2006

Yang F 2015

Overall (1-8quared $=49.5 \%, p=0.078$ )

$-5$

$3.00(-0.96,6.96) \quad 6.09$

$1.30(-3.43,6.03) \quad 4.28$

$-0.10(-3.28,3.08) \quad 9.45$

$-1.50(-2.89,-0.11) \quad 49.54$

$1.40(-2.13,4.93) \quad 7.68$

$1.59(-0.45,3.63) \quad 22.99$

$-0.04(-1.02,0.24) \quad 100.00$ b

Study

ID

WMD $(85 \% \mathrm{Cl}) \quad$ Weight

Bhowmick 2010

Locrubier 2006

Yang F 2015

Overall (1-8quared $=0.0 \%, p=0.501$ )

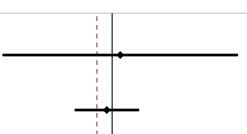

$0.40(-5.72,6.52) \quad 4.59$

$-0.30(-1.96,1.36) \quad 62.67$

$-1.90(-4.19,0.39) \quad 32.74$

$-0.79(-2.10,0.52) \quad 100.00$

d

Study

ID

WMD (95\% Cl) Woight
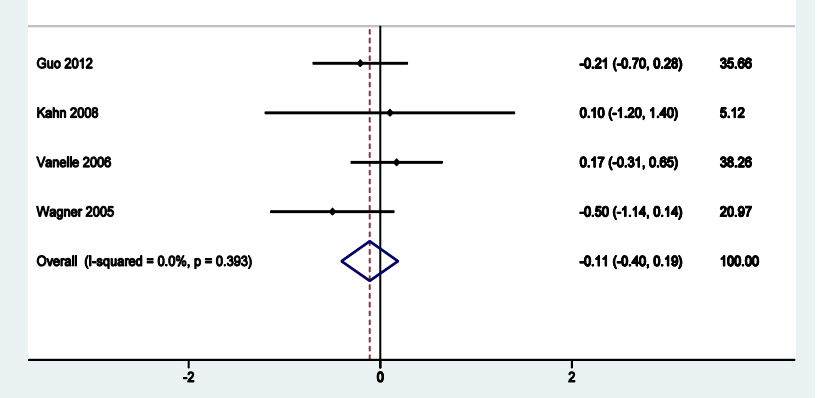

Fig. 4 Forest plots of total scores for four common rating scales of schizophrenia: a PANSS; b SANS; c BPRS; d CGI-SI 
a

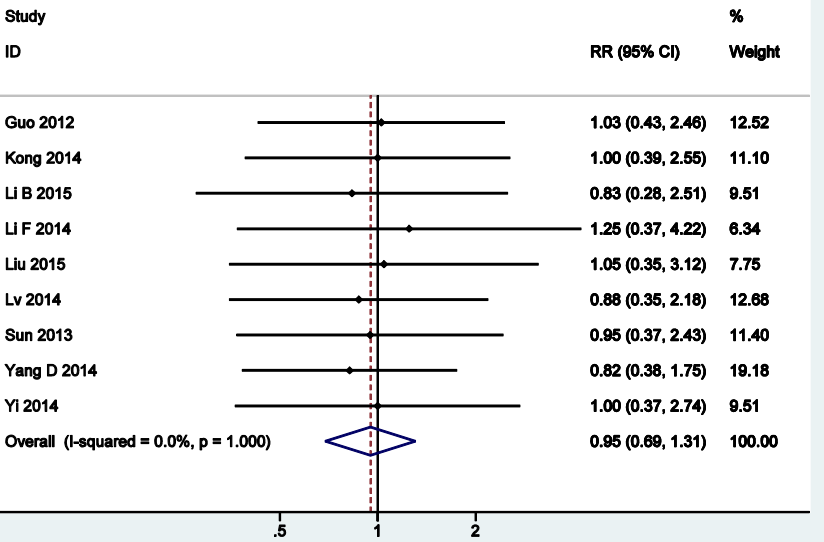

b

Study

$\%$

ID

RR (95\% Cl) Welght

Guo 2012

Kahn 2008

Kong 2014

Li B 2015

LIF 2014

Llu 2015

Sun 2013

Yang D 2014

YI 2014

$0.96(0.56,1.66) \quad 8.23$

$1.01(0.83,1.22) \quad 36.29$

$1.38(0.63,3.00) \quad 4.17$

$0.94(0.56,1.59) \quad 8.86$

$0.94(0.59,1.50) \quad 8.86$

$0.93(0.44,1.97) \quad 4.58$

$1.00(0.62,1.62) \quad 9.10$

$0.88(0.59,1.32) \quad 14.71$

$1.10(0.55,2.18) \quad 5.21$

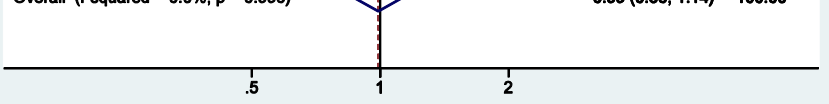

C

Study

ID

RR (95\% Cl) Welght

Guo 2012

Kahn 2008

Kong 2014

Li B 2015

LI F 2014

Liu 2015

Sun 2013

Yang D 2014

Yi 2014

Overall (I-squared $=0.0 \%, p=0.988$ )

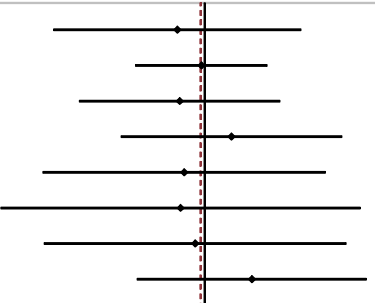

$0.86(0.42,1.74) \quad 9.97$

$0.98(0.67,1.43) \quad 30.14$

$0.87(0.49,1.54) \quad 12.62$

$1.17(0.62,2.20) \quad 10.10$

$0.89(0.39,2.00) \quad 7.57$

$0.87(0.31,2.45) \quad 4.94$

$0.95(0.40,2.26) \quad 6.91$

$1.31(0.68,2.53) \quad 10.18$

$0.78(0.33,1.81) \quad 7.57$

$0.98(0.79,1.21) \quad 100.00$

Fig. 5 Forest plots of proportion of patients defined as a improved, $\mathbf{b}$ much improved and $\mathbf{c}$ very much improved (based on PANSS) 
As for medical costs, the assumption was made that the efficacy and hospitalization rates between both treatments were equivalent; only costs of the adverse events were brought into the analysis. Costs of adverse events were collected from a panel of local clinical experts. As suggested by the clinical experts, in real-world practice, the treatment rates for some of the adverse events (e.g. somnolence, constipation, insomnia) are very low, thus we only considered the cost to treat adverse events that had clinical significance. Probabilities of adverse events were calculated based on the number of events and totals from included trials.

In both the base case scenario and the additional scenario, sensitivity analyses were performed accordingly to examine the stability and robustness of the results. In the univariate sensitivity analysis, unit costs and probabilities of adverse events varied by $\pm 20 \%$. Since daily dosages of antipsychotics vary considerably between different stages of disease progression, we used a large range $-400-800 \mathrm{mg}$ for amisulpride and 5-20 mg for olanzapine - as recommended by Chinese treatment guidelines [9]. In the probabilistic sensitivity analysis, Monte Carlo simulations (1000 times) were performed to test the uncertainty in the base case scenario. Cost differences were calculated and presented in frequency distributions and the probability of which amisulpride was still cost-saving.

\section{Results}

Twenty RCTs with 2000 patients involving treatment with either amisulpride or olanzapine were identified

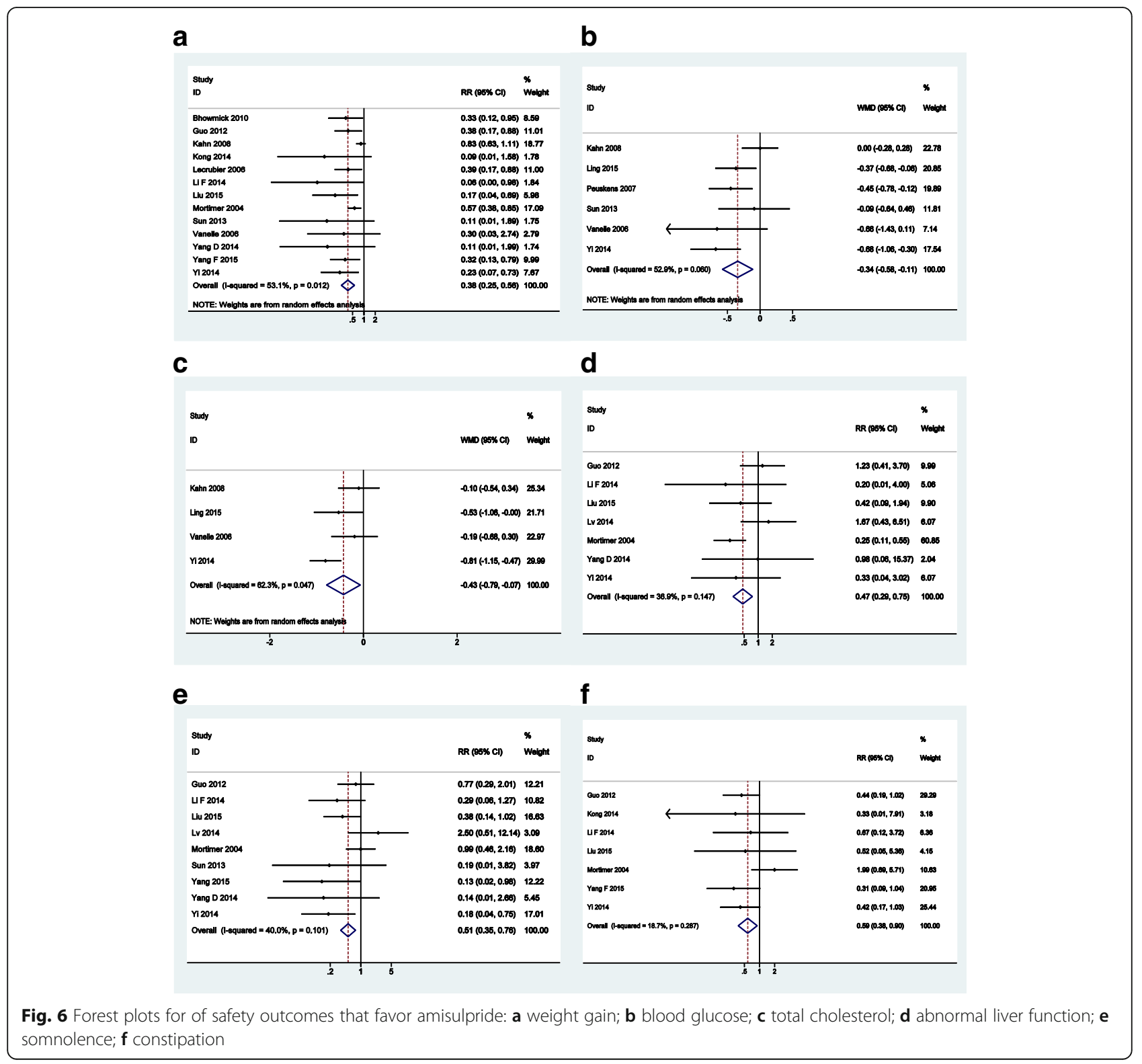


and included as a result of the systematic review. Among these 20 trials, $13(65.0 \%)$ were Chinese studies. The process of study selection and the final results of the search are illustrated below using the PRISMA Flow Diagram in Fig. 1. The treatment groups in each included trial were generally balanced with respect to demographic and clinical characteristics (Table 2). Each enrolled participant had an explicit diagnosis of schizophrenia based on the definitions in the Diagnostic and Statistical Manual of Mental Disorders, 4th Edition (DSM-IV), International Statistical Classification of Diseases and Related Health Problems 10th Revision (ICD-10), Chinese Classification and Diagnosis of Mental Diseases-3rd edition (CCMD3), or Mini International
Neuropsychiatric Interview Plus (MINI-plus) criteria. The results and summary of risk of bias assessment for included studies were summarized in Figs. 2 and 3. The majority of included studies possessed low and/or moderate risk of bias. Selection bias (e.g. unclear random sequence generation, allocation concealment or blinding) was the dominant cause of high and unclear risk of bias.

\section{Comparison of amisulpride and olanzapine on efficacy}

The efficacy profile of olanzapine was similar to that of amisulpride. The results of mean changes from baseline in the PANSS total score showed no difference between amisulpride and olanzapine groups (20 trials, WMD =0.20 , $95 \%$ CI: -1.22 to 0.82 , Fig. 4 ).

\section{a}

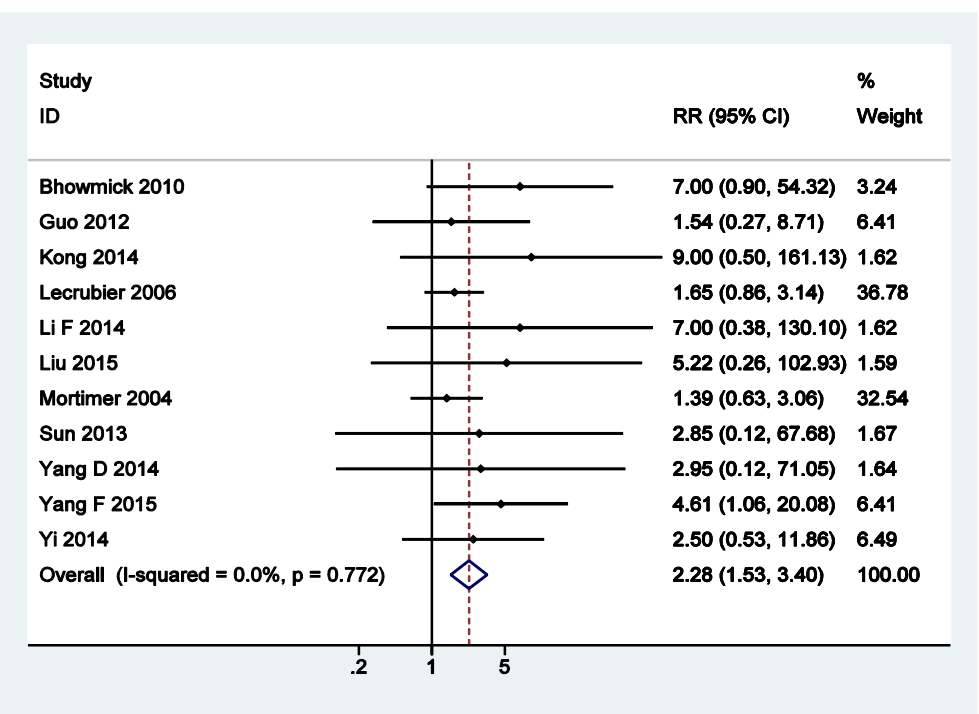

b

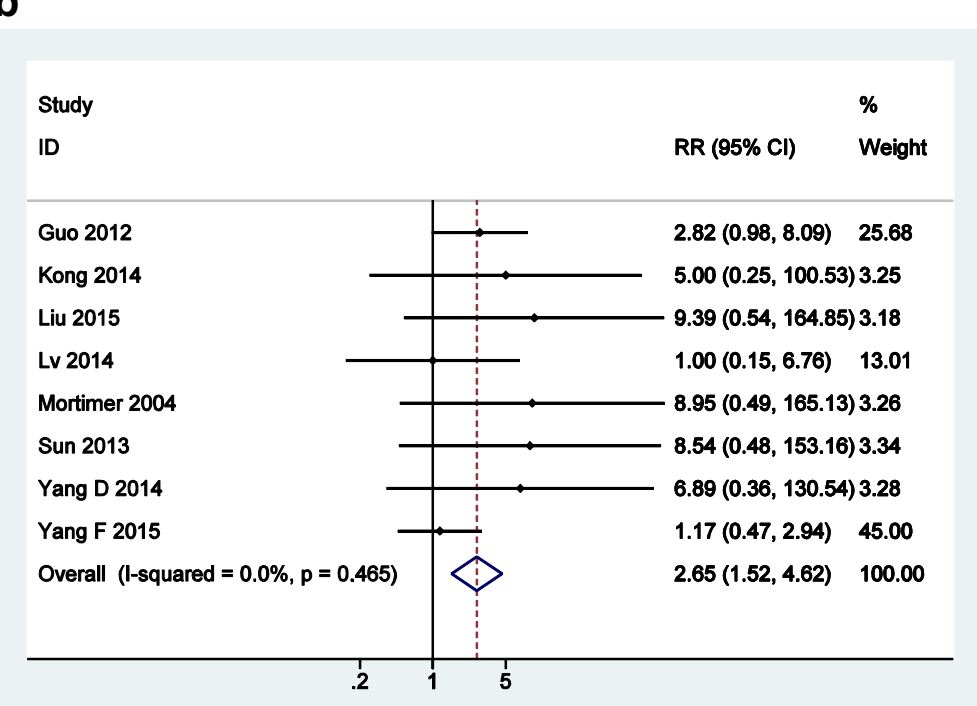

Fig. 7 Forest plots for of safety outcomes that favor olanzapine: a insomnia; b lactation/amenorrhea/sexual hormone disorder 
The proportions of patients assessed as "improved" ( $\mathrm{RR}=0.95,95 \% \mathrm{CI}: 0.69$ to 1.31 ), "much improved" (RR $=0.99$, 95\%CI: 0.86 to 1.14$)$, and "very much improved" $(\mathrm{RR}=0.98,95 \% \mathrm{CI}: 0.79$ to 1.21$)$ were also similar between amisulpride and olanzapine groups (Fig. 5).

Meanwhile, there were no significant difference in effect sizes between the two treatment groups in terms of mean changes from baseline in SANS (WMD $=-0.79$, 95\%CI: -2.10 to 0.52 ), BPRS (WMD $=-0.04,95 \% \mathrm{CI}$ : -1.02 to 0.94 ), and CGI-SI (WMD $=-0.11,95 \%$ CI: -0.40 to 0.19$)$ total scores. The forest plots of efficacy results are presented in Fig. 4.

\section{Comparison of amisulpride and olanzapine on safety}

When comparing amisulpride with olanzapine, the differences were statistically significant among the two patient groups. Amisulpride-treated patients experienced more weight gain over their baseline body weight $(\mathrm{RR}=0.38,95 \% \mathrm{CI}: 0.25$ to 0.56$)$, decreased blood glucose $(\mathrm{WMD}=-0.34 \mathrm{mmol} / \mathrm{L}, 95 \% \mathrm{CI}$ : -0.58 to -0.11 ) and lowered total cholesterol (WMD =$0.43 \mathrm{mmol} / \mathrm{L}, 95 \% \mathrm{CI}:-0.79$ to -0.07$)$. Amisulpride was also significantly superior to olanzapine with lower risks of abnormal liver function (liver transaminase elevation, $\mathrm{RR}=0.47,95 \% \mathrm{CI}: 0.29$ to 0.75 ), somnolence $(\mathrm{RR}=0.51,95 \% \mathrm{CI}: 0.35$ to 0.76$)$ and constipation $(R R=0.59,95 \% C I$ : 0.38 to 0.90$)$. The forest plots of safety outcomes that favor amisulpride are presented in Fig. 6.

On the other hand, amisulpride induced significant higher risks of insomnia $(\mathrm{RR}=2.28,95 \% \mathrm{CI}$ : 1.53 to 3.40) and lactation/amenorrhea/sexual hormone disorder $(\mathrm{RR}=2.65,95 \% \mathrm{CI}$ : 1.52 to 4.62$)$. The forest plots of safety outcomes that favor olanzapine are presented in Fig. 7.

For patients treated with amisulpride, the incidences of EPS ( $R R=3.38,95 \% C I$ : 0.71 to 16.06$)$, akathisia $(R R=1.36$, 95\%CI: 0.90 to 2.06 ) and tremor ( $R R=3.54,95 \% \mathrm{CI}: 0.89$ to 14.11) were higher than those of patients with olanzapine but with no statistical significance. Other AEs such as HDL, LDL, triglycerides, headache, xerostomia, increased salivation, hypotension and abnormal QTc were similar between the two groups. The forest plots of outcomes without statistical significance are presented in Fig. 8.

\section{Cost-minimization analysis comparing amisulpride and olanzapine}

Among 13 included trials in China, 7 reported average doses of amisulpride and olanzapine during the treatment periods. Weighted average dosages from the 7 trials were $551.11 \mathrm{mg}$ per day for amisulpride and $12.73 \mathrm{mg}$ per day for olanzapine (Table 3). Average follow-up time in the 13 included Chinese studies was 3

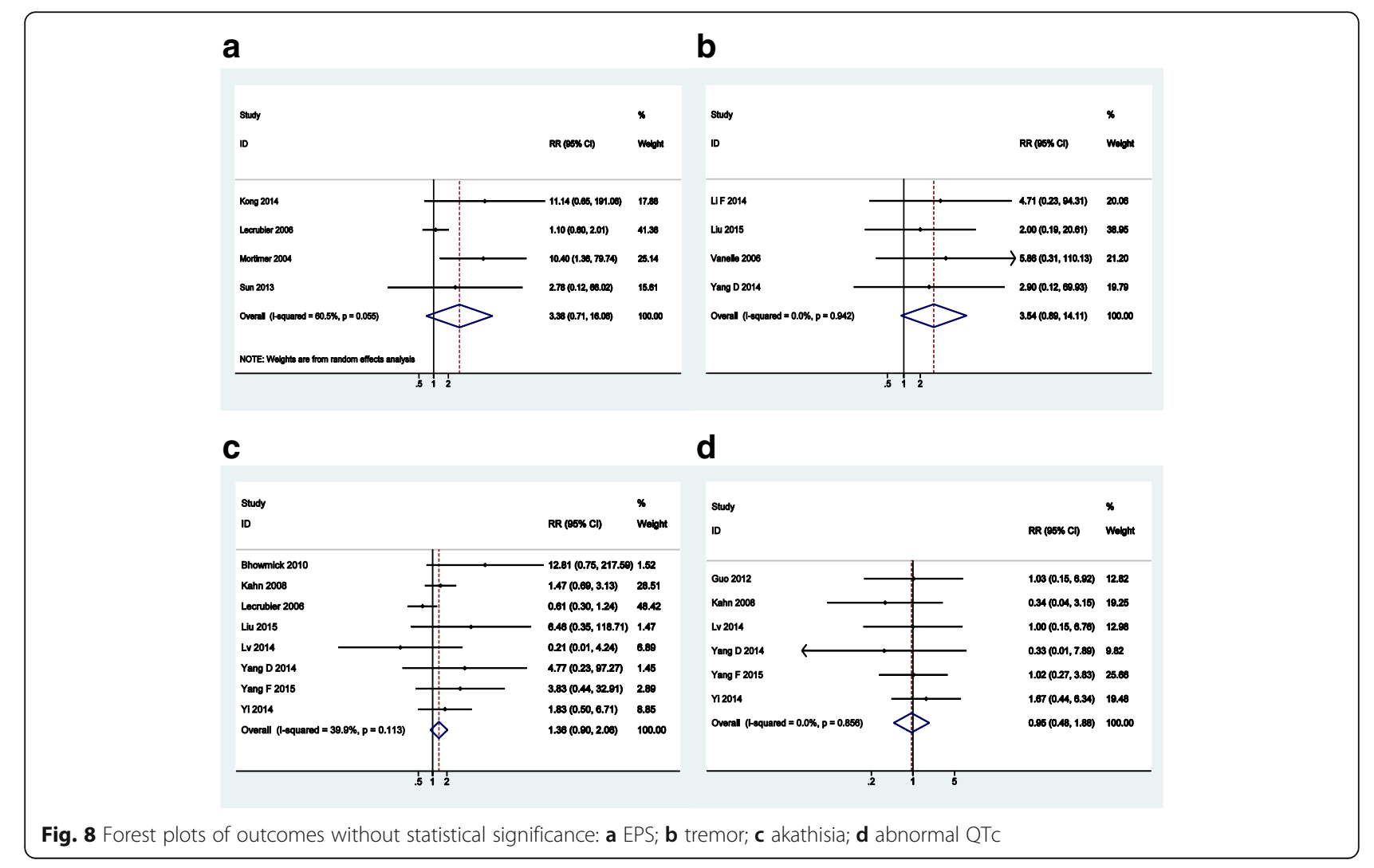


Table 3 Included Chinese studies that reported average daily dosage

\begin{tabular}{lllll}
\hline Study & \multicolumn{2}{l}{ Amisulpride } & & \multicolumn{2}{l}{ Olanzapine } \\
\cline { 2 - 5 } & $n$ & Avg. dosage(mg/d) & & Avg. dosage(mg/d) \\
\hline Yang 2015 [36] & 42 & 222.36 & 43 & 15.27 \\
Yi 2014 [38] & 29 & 503.45 & 29 & 8.50 \\
Lv 2014 [27] & 40 & 642.50 & 40 & 14.12 \\
Yang 2014 [33] & 61 & 600.00 & 60 & 10.00 \\
Guo 2012 [20] & 38 & 857.20 & 39 & 15.00 \\
Chu 2015 [21] & 19 & 465 & 18 & 16.6 \\
Lin 2015 [27] & 30 & 503 & 31 & 12.73 \\
Weight average daily dosage & 551.11 & & & 11.57
\end{tabular}

months. The probabilities of adverse events, costs of adverse events and ranges tested for univariate sensitivity analysis are displayed in Table 4.

\section{Base case scenario}

In the base case scenario, we used the weighted average cost of both original and generic drugs. Unit costs per $200 \mathrm{mg}$ amisulpride and $5 \mathrm{mg}$ olanzapine were 8.40 CNY and $15.05 \mathrm{CNY}$, respectively. The estimated 3-month costs per patient were $2273 \mathrm{CNY}$ for amisulpride and $3615 \mathrm{CNY}$ for olanzapine, with an incremental saving of $1358 \mathrm{CNY}$ per patient.

\section{Additional scenario}

In the additional scenario using original drug costs, unit costs per $200 \mathrm{mg}$ amisulpride and $5 \mathrm{mg}$ olanzapine were 13.53 CNY and 21.90 CNY, respectively. The estimated 3-month costs per patient were $3567 \mathrm{CNY}$ for amisulpride and $5168 \mathrm{CNY}$ for olanzapine, with an incremental cost of $1601 \mathrm{CNY}$ per patient.

\section{Sensitivity analyses}

Results of the univariate sensitivity analyses are displayed in tornado diagrams for both the base case scenario (Fig. 9) and the additional scenario (Fig. 10). Based on our findings, dosage and unit costs of amisulpride and olanzapine demonstrated the largest impacts on cost differences. Amisulpride was consistently seen as the more cost-saving alternative except when the comparison group used the lowest daily dosage $(5 \mathrm{mg}$ ) of olanzapine. Although Chinese treatment guidelines [9] recommend a large dosage range, it is noteworthy to acknowledge that a $5 \mathrm{mg}$-dosage for olanzapine is rare in a real-world setting. In the included Chinese studies, the lowest olanzapine dosage was $8.5 \mathrm{mg}$ daily.

The probabilistic sensitivity analyses demonstrated a 94.6\% probability that amisulpride is a cost-saving alternative, thus confirming the stability and robustness of the base case analysis. Frequency distributions of cost differences are presented in Fig. 11.

Table 4 Cost-minimization analysis comparing amisulpride and olanzapine in the treatment of Chinese patients with schizophrenia

\begin{tabular}{|c|c|c|c|c|}
\hline \multirow{2}{*}{$\frac{\text { Data Input }}{\text { Drug costs }}$} & \multicolumn{2}{|c|}{ Amisulpride } & \multicolumn{2}{|c|}{ Olanzapine } \\
\hline & Mean & Range & Mean & Range \\
\hline Unit drug cost - base case (CNY) & 8.40 & $6.72-10.08$ & 15.05 & $12.04-18.06$ \\
\hline Unit drug cost - scenario (CNY) & 13.53 & $10.82-16.23$ & 21.90 & $17.52-26.28$ \\
\hline Daily dosage (mg) & 565.78 & $400.00-800.00$ & 12.57 & $5.00-20.00$ \\
\hline \multicolumn{5}{|l|}{ Probability of adverse events } \\
\hline Probability of weight gain & 0.15 & $0.12-0.18$ & 0.40 & $0.32-0.48$ \\
\hline Probability of increased blood glucose levels & 0.03 & $0.02-0.03$ & 0.06 & $0.04-0.07$ \\
\hline Probability of liver function damage & 0.06 & $0.04-0.07$ & 0.13 & $0.1-0.16$ \\
\hline Probability of lactation/amenorrhea/sexual hormone disorder & 0.09 & $0.07-0.11$ & 0.03 & $0.02-0.03$ \\
\hline Cost of adverse events (CNY) & Mean & Range & \multicolumn{2}{|c|}{ Data Source } \\
\hline Weight gain & 29 & $23.2-34.8$ & \multicolumn{2}{|c|}{ KOL interview ${ }^{a}$} \\
\hline Increased blood glucose levels & 2111 & $1688.8-2533.2$ & \multicolumn{2}{|c|}{ KOL interview } \\
\hline Liver function damage & 575 & $460-690$ & \multicolumn{2}{|c|}{ KOL interview } \\
\hline Lactation/amenorrhea/sexual hormone disorder & 352 & $281.6-422.4$ & \multicolumn{2}{|c|}{ KOL interview } \\
\hline
\end{tabular}




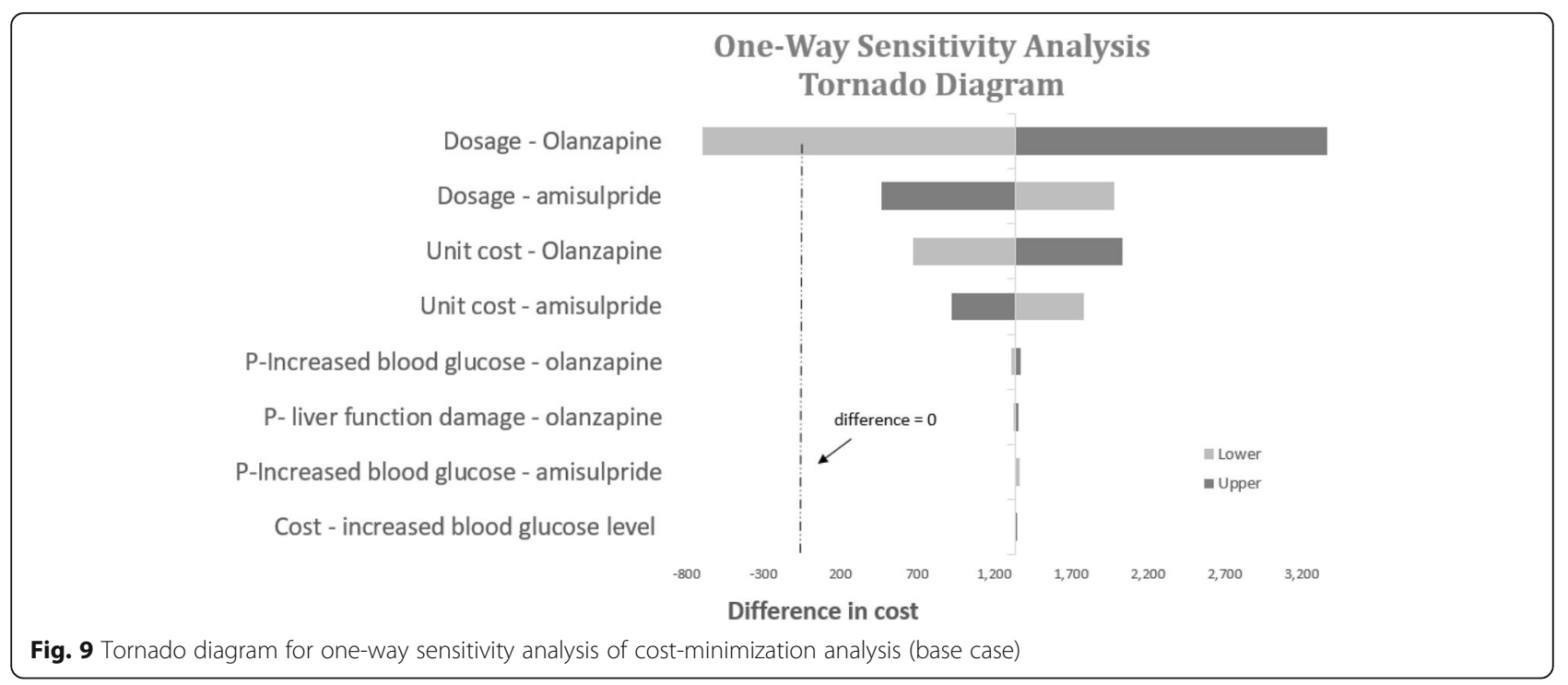

\section{Discussion}

In this comprehensive systematic review and meta-analysis of head-to-head clinical trials between amisulpride and olanzapine, both drugs were similar in terms of treatment efficacy for schizophrenia. There were no significant differences in mean changes from baseline for total scores of PANSS, SANS, BPRS, and CGI-SI between patients treated with these two drugs. The proportion of patients assessed as improved, much improved, and very much improved were also similar between the groups. Additionally, one included trial [18] showed no statistical difference between amisulpride and olanzapine groups on relapse rates. These results were consistent with those in previous systematic reviews and meta-analyses [11]. Other efficacy outcomes such as quality of life (QoL) and general function are also important. However, only six studies reported related outcomes and used different measurement tools respectively. Thus, we did not include the QoL and general function outcomes in our analyses.
In terms of safety and tolerability, amisulpride and olanzapine were both tolerable and showed different characteristics on specific outcomes. Our analyses revealed that amisulpride had significantly more favorable effects than olanzapine for weight gain, blood glucose, and total cholesterol, which indicated a better influence on metabolic parameters. A previous study found a dose-dependent weight gain after 6 weeks of olanzapine treatment due to its antagonism at $5-\mathrm{HT}_{2 \mathrm{C}}$ and $\mathrm{H} 1$ receptors. The results of our study implied that patients with a family or personal history of diabetes, dyslipidemia and obesity should be cautious and attentive to their body weights, fasting blood glucose levels and lipid profiles before starting and receiving olanzapine treatment [19].

Amisulpride also demonstrated superiority for lower risks of constipation, liver transaminase elevation levels and somnolence, while its risks on insomnia and lactation/ amenorrhea/sexual hormone disorder

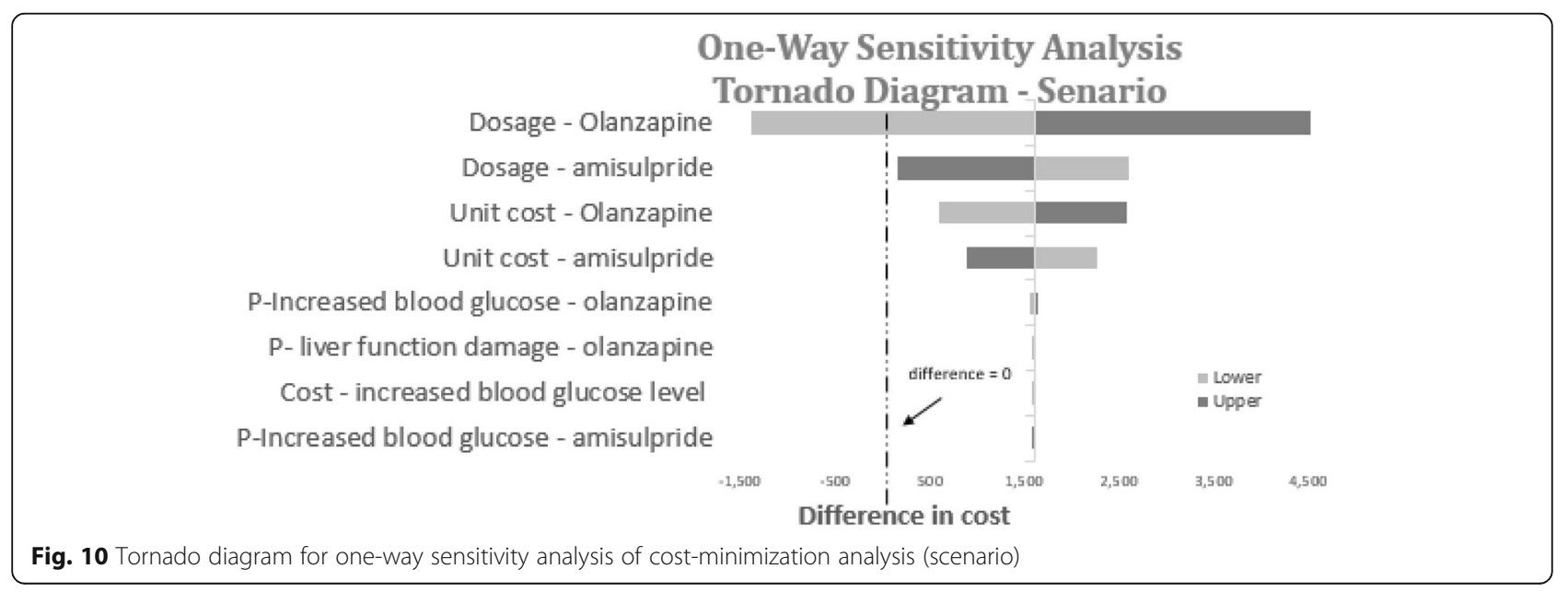




\section{Frequency distribution of cost difference \\ Amisulpride vs. Olanzapine}

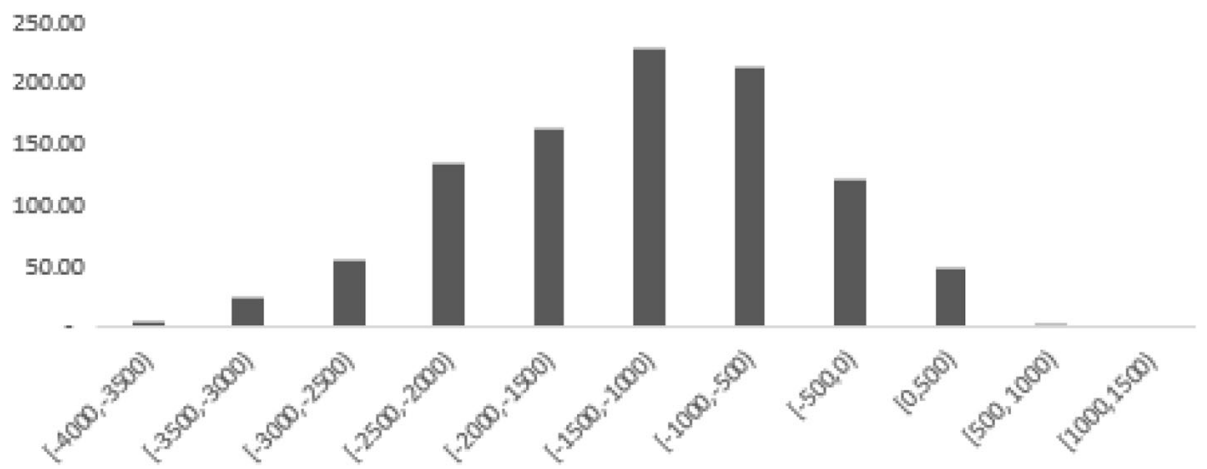

Fig. 11 Frequency distribution of 3-month cost difference for the probabilistic sensitivity analysis

were significantly higher than that of olanzapine. The results were consistent with a previous systematic review [11]. Concerning risks of EPS, akathisia and tremor, although olanzapine showed better safety profile, the results were not significant. Olanzapine showed a better safety profile for EPS, akathisia and tremor, however the results were not significant. More large-scale trials are required to further investigate the differences between the adverse events for amisulpride and olanzapine.

Our study compared amisulpride and olanzapine for the treatment of schizophrenia by analyzing a large number of RCTs. Although one trial included a mix of patients with schizophrenia, schizophreniform and schizoaffective disorder (of which $57 \%$ were schizophrenia patients), this particular trial was nevertheless selected for our study due to its good quality and large sample size. To justify the trial's inclusion, we conducted sensitivity analyses to test the impact of this trial against others, results of which showed no significant differences among all of the outcomes.

Cost minimization analysis showed that amisulpride might act as a cost-saving alternative to olanzapine in the local Chinese setting with a potential saving of $1358 \mathrm{CNY}$ every 3 months for a patient with schizophrenia in the acute phase, and further potential savings in the maintenance phase. In the additional scenario when original drug costs were applied, the potential savings increased to 1601 CNY per patient. Sensitivity analyses demonstrated the robustness of the results, with dosage and unit costs of amisulpride and olanzapine identified as the most sensitive factors.

The funding sources of included studies were also verified. Three of the 13 Chinese studies reported their funding sources as hospitals. Among the 7 foreign studies, 5 reported their sponsorships: Two studies were from Eli Lilly, one study from Sanofi, one from Sun Pharma, and one from a joint grant from AstraZeneca, Pfizer and Sanofi. All eight studies declared that the sponsor(s) exerted no influence on the results of the studies.

This study is the first meta-analysis of amisulpride to include data from Chinese patients and may therefore be used to inform better treatment decision-making as China gains increasing access to amisulpride and olanzapine. Moreover, it is the first study to compare the economic benefits of both medications.

Despite the usefulness of this study, limitations remain. First, as there are several different outcome scales used for schizophrenia patients, data from some scales in the included studies were limited (for example, only one study provided data of relapse rate), thus making it difficult to carry a better meta-analysis with these scales. Secondly, although a majority of included studies carried low and moderate risk of bias, the quality of included Chinese studies was lower than that of foreign studies, especially in terms of unclear bias in random sequence generation, allocation concealment and blinding. High-quality research on Chinese patients is required to assess clinical practices and support guideline recommendations. Thirdly, the heterogeneity of population (such as sex and age differences) included in the trials may affect the efficacy and safety results. Finally, since published cost data for the treatment of adverse events is currently unavailable, cost data were retrieved from clinical expert opinion, which oftentimes require further confirmation by chart reviews, clinical trials or real-world studies. Only drug costs and costs for selected adverse events were taken into account; social costs such as sick absence and unemployment were not considered in the CMA. 


\section{Conclusion}

This study suggests that amisulpride is an effective and well-tolerated antipsychotic drug, and may act as a cost-saving alternative to olanzapine in China. The results may provide an important reference for clinical decision-making in China.

\begin{abstract}
Abbreviations
BPRS: Brief Psychiatric Rating Scale; CCMD3: Chinese Classification and Diagnosis of Mental Diseases-3rd edition; CGI-SI: Clinical Global Impressions Severity or Improvement; CHPA: IQVIA China Hospital Pharmaceutical Audit; Cl: Confidence interval; CMA: Cost-minimization analysis; DSM-IV: Diagnostic and Statistical Manual of Mental Disorders, 4th Edition; EPS: Extrapyramidal symptoms; HDL: High-density lipoprotein; ICD-10: International Statistical Classification of Diseases and Related Health Problems 10th Revision; LDL: Low-density lipoprotein; MINI-plus: Mini International Neuropsychiatric Interview Plus; NICE: UK's National Institute for Health and Clinical Excellence; PANSS: Positive and Negative Syndrome Scale; QTc: QT interval;

RCT: Randomized controlled trials; RRs: Risk ratios; SANS: Scale for the Assessment of Negative Symptoms; UEBMI: Urban Employee Basic Medical Insurance; WMDs: Weighted mean differences
\end{abstract}

\section{Acknowledgements}

We sincerely thank Wei Huang and Liping Zhao for their contribution to help conduct the literature review and data extraction for this manuscript. High tribute shall be paid to Dr. Kaida Jiang from Shanghai Mental Health Center, Dr. Fujun Jia from Guangdong General Hospital, Dr. Xiaoping Wang from Xiangya 2nd Hospital, Dr. Qiang Li from Xi'an Jiaotong University affiliated 1st Hospital, Dr. Hong Deng from Hua Xi Hospital of Sichuan University, and Dr. Li Yi from Wuhan Mental Health Center for their expert opinions on relevant local cost data inputs in the analysis.

\section{Funding}

This study was funded by Sanofi China.

\section{Availability of data and materials}

All data generated or analyzed during this study are included in the published articles.

\section{Authors' contributions}

PM, ZY, LC, SQ, TX and SZ developed the study objective; PM, ZY, and SQ developed the search strategy, conducted the study selection, data extraction, statistical analyses and manuscript writing. XY and SZ provided expert consultations on the contents of the manuscript. The manuscript was reviewed and agreed by all co-authors. All authors approved the final version of the manuscript.

\section{Ethics approval and consent to participate}

Not applicable.

\section{Consent for publication}

Not applicable.

\section{Competing interests}

Chaoyun Li is an employee of Sanofi China. Shuli Qu and Tengbin Xiong are employees of IQVIA China and received research funds from Sanofi China. None of the remaining authors have any personal or financial conflicts of interest.

\section{Publisher's Note}

Springer Nature remains neutral with regard to jurisdictional claims in published maps and institutional affiliations.

\section{Author details}

'Department of Pharmacy, Peking University Third Hospital, N. Huayuan Rd, Beijing, China. ${ }^{2}$ Institute for Drug Evaluation, Peking University Health Science Center, Beijing, China. ${ }^{3}$ Department of Pharmacy Administration and Clinical Pharmacy, School of Pharmaceutical Science, Peking University, Beijing, China. ${ }^{4}$ Health Economics \& Outcome Research, Sanofi, Yanan Rd, Shanghai, China. ${ }^{5}$ Real-World Insights, IQVIA, W. Beijing Rd, Shanghai, China.
${ }^{6}$ Department of Psychiatry, Peking University Sixth Hospital, N. Huayuan Rd, Beijing, China.

Received: 15 January 2018 Accepted: 28 August 2018

Published online: 05 September 2018

\section{References}

1. Schizophrenia overview. https://www.nimh.nih.gov/health/topics/ schizophrenia/index.shtml. Accessed 26 Apr 2018.

2. GBD 2015 Disease and Injury Incidence and Prevalence Collaborators. Global, regional, and national incidence, prevalence, and years lived with disability for 310 diseases and injuries, 1990-2015: a systematic analysis for the global burden of disease study 2015. Lancet. 2016;388:1545-602. https://doi.org/10.1016/S0140-6736(16)31678-6. PMID: 27733282

3. Chan KY, Zhao F-F, Meng S, Demaio AR, Reed C, Theodoratou E, et al. Prevalence of schizophrenia in China between 1990 and 2010. J Glob Health. 2015;5:010410. https://doi.org/10.7189/jogh.05.010410. PMID: 26649171

4. Long J, Huang G, Liang W, Liang B, Chen Q, Xie J, et al. The prevalence of schizophrenia in mainland China: evidence from epidemiological surveys. Acta Psychiatr Scand. 2014;130:244-56. https://doi.org/10.1111/acps.12296. PMID: 24916190

5. Montgomery W, Liu L, Stensland MD, Xue HB, Treuer T, Ascher-Svanum H. The personal, societal, and economic burden of schizophrenia in the People's Republic of China: implications for antipsychotic therapy. Clinicoecon Outcomes Res. 2013;5:407-18. https://doi.org/10.2147/CEOR. S44325. PMID: 23983478

6. Nicholl D, Akhras K, Diels J. Burden of schizophrenia in recently diagnosed patients: healthcare utilisation and cost perspective. Curr Med Res Opin. 2010;26:943-55.

7. Chong HY, Teoh SL, DB-C W, Kotirum S, Chiou C-F, Chaiyakunapruk N Global economic burden of schizophrenia: a systematic review. Neuropsychiatr Dis Treat. 2016; https://doi.org/10.2147/NDT.S96649.

8. Wu J, He X, Liu L, Ye W, Montgomery W, Xue H, et al. Health care resource use and direct medical costs for patients with schizophrenia in Tianjin, People's Republic of China. Neuropsychiatr Dis Treat. 2015;11:983-90. https://doi.org/10.2147/NDT.S76231. PMID: 25897235

9. Zhao J, Shi S. Chinese guidelines for the prevention and treatment of schizophrenia (version 2). 2015.

10. Research and Markets. Investigation Report on China's Olanzapine Market 2015-2019. 2015. https://www.prnewswire.com/news-releases/ investigation-report-on-chinas-olanzapine-market-2015-2019-300125449. html. Accessed 26 Apr 2018.

11. Komossa K, Rummel-Kluge C, Hunger H, Schmid F, Schwarz S, Silveira da Mota Neto Jl, et al. Amisulpride versus other atypical antipsychotics for schizophrenia. Cochrane Database Syst Rev. 2010;1:CD006624. https://doi. org/10.1002/14651858.CD006624.pub2. PMID: 20091599

12. Lin L, Zhao YJ, Zhou HJ, Khoo AL, Teng M, Soh LB, et al. Comparative costeffectiveness of 11 oral antipsychotics for relapse prevention in schizophrenia within Singapore using effectiveness estimates from a network meta-analysis. Int Clin Psychopharmacol. 2016;31:84-92. https://doi. org/10.1097/YIC.0000000000000111. PMID: 26619182

13. García-Ruiz AJ, Pérez-Costillas L, Montesinos AC, Alcalde J, Oyagüez I, Casado MA. Cost-effectiveness analysis of antipsychotics in reducing schizophrenia relapses. Health Econ Rev. 2012;2:8. https://doi.org/10.1186/ 2191-1991-2-8. PMID: 22828390

14. Obradovic M, Mrhar A, Kos M. Cost-effectiveness of antipsychotics for outpatients with chronic schizophrenia. Int J Clin Pract. 2007;61:1979-88. https://doi.org/10.1111/j.1742-1241.2007.01431x.

15. Higgins JPT, Green S (editors). Cochrane Handbook for Systematic Reviews of Interventions Version 5.1.0 [updated March 2011]. The Cochrane Collaboration, 2011. Available from: http://handbook.cochrane.org. Accessed 26 Apr 2018.

16. The guidelines manual | Guidance and guidelines | NICE. https://www.nice. org.uk/process/pmg6/chapter/introduction. Accessed 26 Apr 2018.

17. Higgins JPT, Altman DG, Gøtzsche PC, Jüni P, Moher D, Oxman AD, et al. The Cochrane Collaboration's tool for assessing risk of bias in randomised trials. BMJ. 2011;343:d5928. PMID: 22008217

18. Lecrubier $Y$, Quintin P, Bouhassira M, Perrin E, Lancrenon S. The treatment of negative symptoms and deficit states of chronic schizophrenia: olanzapine compared to amisulpride and placebo in a 6-month double- 
blind controlled clinical trial. Acta Psychiatr Scand. 2006;114:319-27. https:// doi.org/10.1111/j.1600-0447.2006.00887.x. PMID: 17022791

19. Praharaj SK, Jana AK, Goyal N, Sinha VK. Metformin for olanzapine-induced weight gain: a systematic review and meta-analysis. Br J Clin Pharmacol. 2011;71:377-82. https://doi.org/10.1111/j.1365-2125.2010.03783.x. PMID: 21284696

20. Bhowmick S, Hazra A, Ghosh M. Amisulpride versus olanzapine in the treatment of schizophrenia in Indian patients: randomized controlled trial. Aust N Z J Psychiatry. 2010;44:237-42. https://doi.org/10.3109/ 00048670903487134. PMID: 20050717

21. Chu W, Chen Y, Zhao Y, Zhao B, Xu Z, Qiu R, et al. A comparison of six kinds of antipsychotic drugs'effects on the cognitive function in patients with first episode schizophrenia. J Clin Psychiatry. 2015;25:197-9. https://bit. ly/2KdKgFX. Accessed 26 Apr 2018

22. Guo W, Xu H, Zhang X. A randomized and comparative study of amisulpride and olanzapine in treatment of schizophrenia. J Neurosci Ment Health. 2012;12:284-6. https://doi.org/10.3969/j.issn.1009-6574.2012.03.022.

23. Kahn RS, Fleischhacker WW, Boter H, Davidson M, Vergouwe Y, Keet IPM, et al. Effectiveness of antipsychotic drugs in first-episode schizophrenia and schizophreniform disorder: an open randomised clinical trial. Lancet. 2008; 371:1085-97. https://doi.org/10.1016/S0140-6736(08)60486-9. PMID: 18374841

24. Kong Y, Song Y. A control study of amisulpride vs.olanzapine in the treatment of first-episode schizophrenia. J Cli Psychosom Dis. 2014;20:3435,40. https://doi.org/10.3969/j.issn.1672-187X.2014.06.014-0034-03.

25. Li B, Chi Z, Chen B, Yan C. Effects of amisulpride, paliperidone extendedrelease tablets, olanzapine on cognitive and memory function of patients with first-episode schizophrenia and without medication. J Inte Tional Psychiatry. 2015;42:14-7. https://bit.ly/2JrAMWn. Accessed 26 Apr 2018.

26. Li F, Zheng $X$, Feng W. A control study on amisulpride and olanzapine in first episode patients with schizophrenia. 2014;24:121-2. https://bit.ly/ 2FeQDFm. Accessed 26 Apr 2018.

27. Lin $\mathrm{H}$, Miao $\mathrm{H}$. Clinical observation of amoxicillin and olanzapine in the treatment of acute schizophrenia. J Mod Clin Med. 2015;41:130-1. https:// doi.org/10.11851/j.issn.1673-1557.2015.02.018.

28. Liu X, Jin S, Li W. A control study of amisulpride vs olanzapine in the treatment of female schizophrenia. J Clin Psychosom Dis. 2015;21 https:// doi.org/10.3969/j.issn. 1672-187X.2015.02.012-0035-03.

29. Lv Z, Zhou Z, Zhang Y. The treatment of female schizophrenia using Amisulpride and olanzapine. China J Health Psychol. 2014;22:499-501. https://doi.org/10.13342/j.cnki.cjhp.2014.04.009.

30. Mortimer A, Martin S, Lôo H, Peuskens J, SOLIANOL Sudy Group. A doubleblind, randomized comparative trial of amisulpride versus olanzapine for 6 months in the treatment of schizophrenia. Int Clin Psychopharmacol. 2004; 19:63-9. PMID: 15076013

31. Pawar GR, Phadnis P, Paliwal A. Evaluation of efficacy, safety, and cognitive profile of amisulpride per se and its comparison with olanzapine in newly diagnosed schizophrenic patients in an 8-week, double-blind, single-centre, prospective clinical trial. ISRN Psychiatry. 2012;2012:703751. https://doi.org/ 10.5402/2012/703751. PMID: 23738210

32. Sun $X$, Yang J. The curative effects of amisulpride and olanzapine on acute schizophrenia. Chin J Prev Contr Chron Dis. 2013;21:292-3. 296. https://doi. org/10.16386/j.cjpccd.issn.1004-6194.2013.03.048.

33. Vanelle J-M, Douki S. A double-blind randomised comparative trial of amisulpride versus olanzapine for 2 months in the treatment of subjects with schizophrenia and comorbid depression. Eur Psychiatry. 2006;21:52330. https://doi.org/10.1016/j.eurpsy.2006.09.003. PMID: 17113759

34. Wagner M, Quednow BB, Westheide J, Schlaepfer TE, Maier W, Kühn K-U. Cognitive improvement in schizophrenic patients does not require a serotonergic mechanism: randomized controlled trial of olanzapine vs amisulpride. Neuropsychopharmacology. 2005;30:381-90. https://doi.org/10. 1038/s.npp.1300626. PMID: 15578006

35. Yang D, Chen J, Chen Y, Peng H. Comparative study of Amisulpride vs .Olanzapine for the treatment of schizophrenia. J Clin Res. 2014;31:479480,483. https://doi.org/10.3969/j.issn.1671-7171.2014.03.022.

36. Yang F, Zhang C, Wen L. A control study of amisulpride vs olanzapine in the treatment of schizophrenia characterized by negative symptoms. J Clin Psychosom Dis. 2015;21:32-34,48. https://doi.org/10.3969/j.issn.1672-187X. 2015.02.011-0032-04
37. Yao K, Zhou Q, Sui Y. A comparative study of sulforam and olanzapine on first - episode schizophrenia. Anhui Med J. 2016;37:80-2. https://doi.org/10. 3969/j.issn.1000-0399.2016.01.026.

38. Yi J, Hu Y, Wan Q. Comparative study on effects of amisulpride and olanzapine on glucose and lipid metabolism in patients with aged schizophrenia. J Neurosci Ment Health. 2014;14:400-402,405. https://doi.org/ 10.3969/j.issn.1009-6574.2014.04.022.
Ready to submit your research? Choose BMC and benefit from:

- fast, convenient online submission

- thorough peer review by experienced researchers in your field

- rapid publication on acceptance

- support for research data, including large and complex data types

- gold Open Access which fosters wider collaboration and increased citations

- maximum visibility for your research: over $100 \mathrm{M}$ website views per year

At BMC, research is always in progress.

Learn more biomedcentral.com/submissions 